\title{
Um intelectual "orgânico": Octavio Pires e a elaboração da Revista Educação e Ensino, editada no Pará no final do século XIX
}

\author{
An intellectual"organic": Octavio Pires and development Review Education and \\ Training, edited in Para in XIX century final
}

Kelly Katia Damasceno

Doutoranda em Educação pela

Universidade Federal do Pará

kkdamasceno@hotmail.com

\section{Sônia Maria da Silva Araújo}

Doutora em Educação

Professora do Instituto de Ciências da Educação da Universidade Federal do Pará ecosufpa@hotmail.com

\begin{abstract}
Resumo: Este artigo tem como objetivo socializar a contribuição de Octavio Pires, professor normalista e intelectual paraense, na última década do século XIX, que dedicou parte da sua vida a dirigir a Revista Educação e Ensino. A estratégia metodológica adotada foi a pesquisa bibliográfica e documental. $\mathrm{O}$ referencial teórico perpassou os escritos de Gramsci (2001), Semeraro (2006), Viana (1987), Marcelo Garcia (1999), entre outros. Consideramos que a contribuição de Octavio Pires é de fundamental importância, pois possibilitou aos professores, sobretudo, às professoras primárias, a reflexão, discussão e proposição sobre os inúmeros desafios pertencentes à carreira docente e à Instrução Pública do Estado. A propositura desse texto é que outros estudiosos e pesquisadores da educação brasileira, principalmente, paraense, possam realizar a análise aprofundada da legislação aprovada pelo Congresso Estadual, no final do século XIX.
\end{abstract}

Palavras-chave: Octavio Pires, Revista Educação e Ensino, Professor-normalista, Intelectual.

\begin{abstract}
This article aims to socialize the contribution of Octavio Pires, normalista and intellectual teacher Pará, in the last decade of the nineteenth century, who devoted part of his life in front of the direction of the Education and Training Magazine. The methodological strategy adopted was bibliographic and documentary research. The theoretical pervaded the writings of Gramsci (2001), Semeraro (2006), Viana (1987), Marcelo Garcia (1999), among others. We believe that the contribution of Octavio Pires is of fundamental importance, to enable teachers, especially primary school teachers, reflection, discussion and proposal on the numerous challenges pertaining to the teaching profession and public education in the state. The bringing of this text is that other scholars and researchers of Brazilian education, especially Pará, can perform in-depth analysis of the legislation passed by the State Congress, in the late nineteenth century.
\end{abstract}

Keywords: Octavio Pires, Magazine Education and Training, Professor normalista, Intellectual. 
Baseado nas ideias de Bloch (1976: 61), para quem "tudo quanto o homem diz ou escreve $[\ldots]$ pode e deve informar a seu respeito", este artigo tem como objetivo socializar a contribuição de Octavio Pires para a educação paraense no último quadrante do século XIX. Trata-se de um professor normalista e intelectual do Pará que dedicou parte da sua vida à função de diretor da Revista Educação e Ensino. Nesta função pôde publicar reflexões e discussões importantes acerca da educação local, nacional e mundial, como a que realizou quanto à "denúncia" da credibilidade dos exames finais realizados nas duas escolas secundárias de Belém, dentre elas, o Lyceu Paraense ${ }^{1}$, como poderemos ler com maiores detalhes ao longo deste texto.

A estratégia metodológica adotada foi pesquisa bibliográfica e documental. De acordo com Gil (2002: 62-63), a pesquisa documental apresenta algumas vantagens, por ser "fonte rica e estável de dados": não implica altos custos, não exige contato com os sujeitos da pesquisa e possibilita uma leitura aprofundada das fontes. Ela é semelhante à pesquisa bibliográfica, segundo o autor, e o que as diferencia é a natureza das fontes, sendo a documental realizada com material que ainda não recebeu tratamento analítico, ou que ainda pode ser reelaborado de acordo com os objetivos da pesquisa.

Corrobora com a ideia acima, Pádua ao dizer que a pesquisa documental

é aquela realizada a partir de documentos, contemporâneos ou retrospectivos, considerados cientificamente autênticos (não fraudados); tem sido largamente utilizada nas ciências sociais, na investigação histórica, a fim de descrever/comparar fatos sociais, estabelecendo suas características ou tendências [...] (1997: 62).

Para esta pesquisa os dados documentais foram fornecidos pelo Centro Cultural Tancredo Neves - CENTUR. No CENTUR foi possível localizar trinta e três exemplares da Revista Educação e Ensino (1891 a 1895).

Pela contribuição dada pelo professor Octavio Pires à educação paraense, compreendemos que se trata de um intelectual e buscamos em Gramsci o conceito, para quem

todos os homens são intelectuais, mas nem todos assumem essa função na sociedade. A escola, o partido, a fábrica, a participação em organizações etc.,

\footnotetext{
${ }^{1}$ Liceu Paraense foi o único estabelecimento de ensino secundário, criado em 1841, localizado em Belém do Pará e mantido pelo Governo Estadual.
} 
são espaços criadores de intelectuais. A escola é o instrumento para elaborar os intelectuais de diversos níveis. A complexidade da função intelectual nos vários Estados pode ser objetivamente medida pela quantidade de escolas especializadas e pela sua hierarquização: quanto mais extensa for a "área" escolar e quanto mais numerosos forem os "graus verticais" da escola, tão mais complexo será o mundo cultural, a civilização, de um determinado Estado (GRAMSCI, 2001: 21 apud SANTOS, 2009: 151, grifos do autor).

Para Semeraro o conceito de intelectual está "intimamente entrelaçado nas relações sociais, pertencentes a uma classe, a um grupo social vinculado a um determinado modo de produção (2006: 376)". Ainda segundo Gramsci (apud SANTOS, 2009) e Semeraro (2006), intelectuais orgânicos fazem parte de um organismo vivo e em expansão, e são responsáveis por construir o projeto da sua classe a partir das articulações das organizações políticas e culturais da sociedade.

Neste sentido, compreendemos que o professor normalista Octavio Pires foi um intelectual orgânico que ao publicar mensalmente a única revista dedicada à educação no Pará, final do século XIX, bem como lecionar no Colégio Minerva, pode contribuir para o projeto educacional do estado paraense.

Outra questão a destacar acerca da contribuição de Octavio Pires é o caráter político que expressava em seus artigos. Ao analisar, por exemplo, o Projeto de Lei sobre a Instrução Pública, demonstra profunda clareza das articulações econômicas e sociais das quais estão envolvidas a educação. Conforme René Rémond (2003 apud SIRINELLI, 2003: 231): “o comportamento político dos intelectuais mereceria por si só um estudo". Ainda na análise do Projeto de Lei publicada na Revista Educação e Ensino, Octavio Pires demonstra postura de defesa à política liberal presente na construção da república brasileira.

\section{O Final do Século XIX e a Educação no Pará}

Como em todo o território colonial, também na educação paraense há presença dos jesuítas, portanto, com influência religiosa. Em 1727, houve uma determinação dos portugueses para que os missionários ensinassem a língua portuguesa aos indígenas, ao alegarem que a língua dos "selvagens" prejudicava a relação entre os colonizadores e 
colonos. A partir de 1733, o ensino de leitura e escrita, as quatro operações da aritmética, a filosofia, o latim, a teologia e a música, é facultado às crianças.

Em 1759, com a Reforma Pombalina, a coroa portuguesa ordena que os missionários jesuítas deixem Portugal e todo o território pertencente a este reino. A situação da instrução pública brasileira, em geral, e, também, da paraense, em particular, se torna ainda mais limitada e frágil.

Nos primeiros anos do século XIX, a instrução pública paraense recebe algumas doações de D. João VI que chega ao Brasil no ano de 1808, fugindo da Guerra ocorrida na Europa.

A chegada da família real na colônia representa certo "avanço" para a educação brasileira, como a inauguração da primeira biblioteca, constituída pelo acervo particular de El Rei D. João VI.

No entanto, o conde de Villa-Flôr, governador do Pará em 1818, percebe a profunda indiferença quanto à oferta educacional proporcionada à população paraense, e se propõe a combatê-la. Assim, realizou uma sessão solene com a comunidade, em que se comprometeu em apoiar todos aqueles que desejassem cumprir o importante dever da educação dos filhos (VIANNA, PARÁ/SEDUC, 1987).

Contudo, mesmo diante de tal empenho, a proposta de fortalecer a educação pública paraense é deixada em segundo plano, quando o governador conde de Villa-Flôr foi substituído por Alberto Patroni ${ }^{2}$, que tinha como maior preocupação o "abafar" a explosão patriótica do povo que ameaçava o poder monárquico da coroa portuguesa.

No período monárquico o que se percebe é a falta de ações por parte do poder público para com a questão educacional marcada pelo descaso, pela falta de escolas, pela falta de professor apto ao magistério, o que resultou em uma colônia de crianças e adultos em sua maioria não alfabetizados.

Somente quase meio século depois da proclamação da independência, em 1871, é que no Pará foi autorizada a criação da escola normal. Porém, mais uma vez, diante do descaso e descompromisso das autoridades públicas, é decretado, em 1885, que a escola normal seja anexada ao Lyceu Paraense, este também se encontrava em ambiente de caos e desordem.

\footnotetext{
${ }^{2}$ Filipe Alberto Patroni Martins Maciel Parente. Nasceu em Belém (PA) no ano de 1798 e faleceu em Lisboa, Portugal, no ano de 1866. Foi advogado, jornalista e político. Disponível em: <http://www.consciencia.org/filipe-alberto-patroni-martins-maciel-parente〉. Acesso em: 15 jun. 2015.
} 
Em 1889, num contexto de proclamação da república, a educação é marcada pelo discurso da Reforma de Benjamim Constant, caracterizado pelo positivismo e liberalismo, que declara a laicidade do ensino, gratuidade da escola primária, substituição do predomínio de ensino literário pelo científico. O país inicia o período republicano com $75 \%$ da população analfabeta, segundo o recenseamento de 1906, publicado pela diretoria geral de estatística (BRASIL, 1916 apud BOMENY, 2003, p.2).

Saviani (2009: 144) denomina este período de "estabelecimento e expansão do padrão das Escolas Normais (1890-1932), cujo marco inicial é a reforma paulista da Escola Normal tendo como anexo a escola-modelo". Neste período a questão da educação e da formação de professores acena certa preocupação por parte do poder público, pois uma das bandeiras dos republicanos era a instrução pública para todos os brasileiros.

No Pará, em 1891, o Dr. Lauro Sodré ${ }^{3}$ adotou novo plano de ensino e regulamentou a escola normal, o que representou um grande avanço para a instrução profissional e a formação docente. Em meio a reformas federais e ações estaduais, o ensino paraense saltou de 67 para 100 matrículas entre 1890 a 1891 (VIANA, PARÁ/SEDUC, 1987).

Segundo Viana (1987), o período republicano no estado também foi marcado pela criação do Lyceu de Artes e Ofícios Benjamim Constant, do Orfanato Paraense, do Instituto Cívico Jurídico Paes de Carvalho e da Escola de Comércio, além da inclusão do ensino noturno para os trabalhadores.

Ainda segundo Viana (PARÁ/SEDUC, 1987),

A critica conscienciosa nos leva a concluir francamente que, em matéria de instrucção pública, o decennio republicano representa um período de completa reorganização e de vida; de 1889 data uma nova orientação, mais pedagógica e consequentemente mais proveitosa.

Entretanto a tarefa da patriótica obra da difusão e aperfeiçoamento do ensino publico ainda se apresenta pesada e longa; em dez anos apenas seria absurda exigencia querer extinctos todos os perniciosos resultados de séculos de atraso e incúria. [...] (VIANNA, PARÁ/SEDUC, 1987).

\footnotetext{
${ }^{3}$ Lauro Nina Sodré e Silva, nascido em Belém no ano de 1858, falecido no Rio de Janeiro em 1944. Foi o primeiro governador do estado do Pará, eleito pelo Congresso Constituinte Paraense, em 1891. Disponível em: 〈https://pt.wikipedia.org/wiki/Lauro_Sodr\%C3\%A9>. Acesso em: 15 jun. 2015.
} 
É neste contexto republicano que a Revista Educação e Ensino passa a circular, no ano de 1891. A seguir destacamos alguns aspectos mais específicos deste periódico que circulou entre o público educacional do Pará no final do século XIX.

\section{A Revista Educação e Ensino (1891 a 1895)}

Os registros encontrados no Centro Cultural Tancredo Neves - CENTUR indicam a probabilidade da Revista Educação e Ensino ter iniciado sua circulação mensal a partir de Janeiro de 1891, sendo a data de término desconhecida. No mesmo centro - Setor de Obras Raras - foram localizados exemplares datados de Agosto de 1891, com o intervalo de numeração que vai do volume $1, \mathrm{n}^{\circ} 8$, ao volume $5, \mathrm{n}^{\circ} 9$, de 1895 . Observamos que há uma sequência cronológica de edição do periódico, ainda que o CENTUR não tenha em seu arquivo todos os números publicados.

No volume $1, \mathrm{n}^{\circ}$ 9, o diretor Octavio Pires deixa claro que o objetivo da revista é contribuir com a formação das professoras primárias no que tange às resoluções referentes ao magistério, aos estudos de letras, das ciências e das artes, entre outros. Conforme trecho da revista em estudo, v. $1, \mathrm{n}^{\circ}$ 9:

Senhoras professoras, esta Revista não é nossa: ella vos pertence toda inteira. É a única existente n'este Estado, consagrada exclusivamente á vossa classe, dedicada inteiramente aos estudos da vossa profissão, constituída tão somente em vehiculo dos modernos progressos pedagógicos. Por ella conhecereis os actosmais importantes, effectuados mensalmente na Directoria que vos rege; por ella sabereis todos as resoluções tomadas a respeito vosso pelo Conselho Superior da Instrucção Publica, suprema autoridade da vossa classe; por ella tereis sciencia das modificações capitães, em matéria de instrucção e educação, havidas no paiz e nas principaes nações do globo; por ella recebereis lições fecundas dos mestres, sobre os vários assumptos de letras, sciencias e artes, que dizem respeito intimo ao que deveis aprender, ao que vos deve instruir, ao que deve constituir o vosso apanágio e orgulho intelectual (PIRES, 1891a: 145).

Neste trecho é evidenciado também que, naquele momento, a Revista era a única que se dedicava a assuntos específicos à educação no estado paraense, e, ainda, que tinha a intenção de contribuir com a formação das professoras. 
Em outro trecho, do v.1, n. 9, o diretor da Revista, Octavio Pires, é incisivo quanto à fragilidade da profissão docente no que tange aos conhecimentos da docência.

Quando pretendemos soerguer um pouco do pó em que até então rastejam os créditos do professorado primário; quando nos esforçamos por facilitar-lhe as fontes, os meios mais cômodos e certos de robustecer a sua anemiada inteligência; quando intentamos guiá-lo pela estrada mais ampla e reta, aos conhecimentos da pratica mais vantajosa ao desempenho da sua missão; quando nos convencemos de que prestamos-lhe um dos maiores auxílios, incentivando-o ao estudo sério das doutrinas pedagógicas, e facultando-lhe o modo mais econômico de dar publica expansão ás suas laboriosas locubrações: sentimos nos lábios o fel do desgosto, na fronte, as rugas da contrariedade e no coração, o confrangimento da tristeza, ante a repulsa com que nos mimosearam as que, talvez mais do que todas, necessitem aprender a maneira de lavar condignamente a mancha pública do desconceito profissional em que jazem. N'este ponto, o corpo docente do interior do Estado tem-se manifestado mais na altura do seu nobre sacerdócio. É que nem sempre o melhoramento do meio significa a recompensa ao saber e á aptidão: algumas vezes é isso um mero efeito do patrocínio escandaloso, tão pernicioso á classe de que falamos, tão prejudicial à infância estudiosa, tão incompatível com os sãos princípios de retidão e justiça do nosso regime. (PIRES, 1891a: 145).

Diante dessa fragilidade profissional, Octavio Pires se demonstra indignado com o professorado primário ao perceber que muitos não compreendem a intenção da publicação do periódico.

É triste, é vergonhoso, é deplorável o modo como ha sido compreendida a utilidade d'esta Revista por algumas representantes do magistério primário, n'esta capital.

É incrível, é lastimoso, é revoltante mesmo, o menosprezo com que foi recebido este periódico no seio das que pretendam ganhar foros de preceptora ilustrada (PIRES, 1891a: 145).

A indignação, desvelada no texto acima, culmina com a inquietação presente na coluna "Pedagogia - Higiene Escolar e suas vantagens" (v. 1 - no 8), que trata da Higiene 
Escolar, do descaso do poder público e da responsabilização injusta ao professorado que recebe uma má formação profissional. Octavio Pires diz:

[...] No Brasil, n'uma ou n’outro Estado tem-se procurado fazer alguma cousa em relação ao importante assumpto de que vimos de ocupar-nos; n’este, com pesar o digo, nada absolutamente temos feito.

É tempo de fazer-se alguma cousa em relação a este importante assumpto.

A causa é nacional, o objetivo humanitário á salvação da futura geração. [...]

D’esta criminosa indiferença nasceu o descalabro da instrução publica.

No entanto não é raro ver acusar-se o professorado não só pela sua incompetência, como pelos resultados todos negativos que apresenta a instrução publica; não é raro ver-se acusar o professorado por faltas que não são suas, porque tudo isso é devido á péssima instrução que recebeu em estabelecimentos do governo, com fiscalização oficial, e que estavam muito longe de atingir o seu fim, porque a começar pelas casas onde funcionavam e terminar pelos compêndios e métodos adoptados, em tudo se notava a ausência completa da pedagogia.

É tempo de agir; governo e cidadãos, sem exclusão de classe, nem de política, cada qual deve concorrer com o seu prestigio e esforços, para ser levado a efeito este grande empreendimento, porque é geral o benefício.

É incontestavelmente axiomática ser a higiene pedagógica a mais importante de todas (PIRES, 1891a: 130, grifo nosso).

Destacamos aqui o trecho em que Octavio Pires (1891) chama a atenção para a questão da má formação docente, um problema que aflige nosso país desde o período colonial e que, ainda hoje, é um dos aspectos problemáticos da educação nacional.

No volume $1, \mathrm{n}^{\circ} 10$, Octavio Pires faz uma análise sobre mudanças ocorridas quanto ao regulamento do ensino primário no ano de 1891, mas declara que "[...] Só a estabilidade das leis reformadoras, com o lento perpassar dos dias e dos anos, é que sazonam os pomos do porvir. Por enquanto estamos na época da inflorescência, e só depois das flores é que os frutos brotam” (PIRES, 1891c:162), ou seja, as sementes foram plantadas, as flores já apareceram, mas os frutos ainda estão por aparecerem e serem colhidos. 
[...] a ultima lei sobre este ramo da administração publica, [...], vasada, muito embora, no molde da reforma de 1890, trouxe-lhe alterações profundas, cujos efeitos convém atentamente observar.

É assim que, entre outras largas modificações, que de espaço, em futuros números, iremos indigitando e discutindo, apresentam-se-nos a redução, quase de metade, do tempo destinado ás aulas, que passaram a funcionar uma só vez ao dia, e a conservação dos mesmos plano e programa de estudos, que apensar não serem ainda os mais completos, são, entretanto, os mais amplos que se tem até o presente formulado, n'este Estado, proporcionalmente a duas sessões de aulas diárias.

A experiência mudamente nos convencerá da necessidade ou de duplicarmos as aulas ou de cortarmos o programa, sob pena de vermos aumentar-se naturalmente o tirocínio escolar de 6 para 7 ou mais anos. (PIRES, 1891c: 162)

Como destaque às mudanças e reformas ocorridas em relação aos anos anteriores, o diretor revela preocupação quanto à reorganização do horário de aula que, de 5 horas com intervalo de 3 horas, passa a ser de 4 horas e meia, com intervalos de 10 minutos. Conforme Octavio Pires (1891c: 162), “[...] Vae n'esta disposição um prejuízo certo de meia hora todos os dias. [...]". Outra apreensão revelada é quanto ao horário do início das aulas, que antes era às 8 h00 e passa para 07h30. Segundo o diretor da Revista Educação e Ensino, essa mudança pode acarretar prejuízo às crianças da escola pública, em sua maioria oriunda de famílias paupérrimas, que até às $07 \mathrm{~h} 00$ se encontram envolvidas com afazeres domésticos, sendo que, das $07 \mathrm{~h} 00$ às 07h30, se ocupam com os preparos para a ida à escola. Assim, só conseguiriam chegar aos bancos escolares às $08 \mathrm{~h} 00$, perdendo mais meia hora de estudos.

Ainda neste sentido, o diretor observa que 4 horas de estudos corridos é um método antipedagógico, se se considera as características físicas dos alunos que estão em plena agitação corporal. Conforme segue,

Este método de reter-se diariamente por tão longo prazo, presas aos bancos de estudo, crianças, cuja natureza reclama a agitação corporal, para o seu regular desenvolvimento físico e de certo o mais antipedagógico possível. Se é verdade que o adulto, já acostumado aos labores da inteligência, pouco ou nenhum resultado lucra do tempo empregado em seus estudos, quando estes 
excedem a 3 horas consecutivas, pois que a fadiga sobrevem logo, com que direito se pretende exigir um resultado positivo, n’este sentido, aos que têm contra si, não só esta falta de habito, como a própria organização, a pedir-lhes movimento e liberdade?

[...] trabalho lucrativo fica reduzido somente a 3 horas por dia, quando muito. Em um espaço de horas tão exíguo, perguntamos, poderá um professor, por mais ativo e reforçado que seja, leccionar, com proveito geral, a 40, 50 e mais alunos, todas as partes de que constam o referido programa de ensino? (PIRES, 1891c: 162).

Ao questionamento posto, o próprio diretor responde que só será possível êxito se houver aumento do número de aulas ou redução do programa escolar. Em suas palavras diz: "De outra maneira, veremos alunos terminarem os seus 06 annos de tirocínio, sem terem concluído o curso superior escolar.” (PIRES, 1891c: 162).

Finaliza a análise dizendo do desejo e da convicção que as reformas progressistas implantadas na instrução primária, após alguns retoques e adaptações aos meios e costumes, darão esplendidos e lucrativos resultados.

A Revista Educação e Ensino, no ano 1892, é iniciada com o volume 2, número 1, em que o diretor traz palavras de esperança para com a instrução pública paraense à luz do período republicano.

Ele concebia a República como “[...] o calor vivificante do estímulo pela mais profícua difusão da instrucção entre o povo, que estiolava-se entorpecido nos gelos da mais glacial ignorância.” (PIRES, 1892a: 1).

Completa dizendo, "O domínio dos conhecimentos humanos entre os habitantes de um paiz é o triumpho breve e seguro da sua autonomia e independência. Não sofre com certeza passivamente o pesado jugo da escravidão politica uma população esclarecida nos seus direitos cívico e perfeitamente consciente do seu pleno valor" (PIRES, 1892a: 1).

O diretor esclarece, ainda, que não basta o país ter códigos visando a democracia, não basta denominar-se uma República, antes de tudo, é necessário ensinar os filhos a "saborear a doçura dos frutos d'esta arvore - República"; instrui-los na maneira de sustentar com "denodo e galhardia o altivo pavilhão"; educá-los na ciência dos novos códigos que possuem, dos novos direitos que lhe são dados, em uma só frase, na ciência da própria administração, do seu próprio governo (PIRES, 1892b: 1) 
Salienta o intelectual a importância da educação quando diz que a ignorância para uma nação republicana é o mesmo que "um sol sem nuvem, para uma família de cegos" (PIRES, 1892b: 1).

Octavio Pires finaliza a coluna tratando dos esforços necessários para com a preparação do professorado primário, que é "incompleta, fraca e anêmica, que apenas lhe concedia o ex-reinado da sepulta dinastia" (PIRES, 1892b: 2). Todavia, ele afirma esperanças no futuro da pátria em nome das instituições politicas vencedoras, ou seja, republicanas.

No volume 2, dos números de 2 a 11, a coluna assinada pelo diretor Octavio Pires, na Revista Educação e Ensino, trata da Higiene dos Internatos no tocante a: Localização, Edificações, Nutrição, Recreio, Exercícios Físicos, Saúde de cada Educando e Higiene da Inteligência.

Neste texto destacamos o último item tratado, em que o diretor enfatiza a necessidade dos mestres estarem atentos à disciplina do ensinar e a distribuir o tempo das atividades oferecidas aos alunos. Segundo Octavio Pires (1892), não adianta oferecer ao aluno do primário um compêndio de instrução secundária. Ou ainda, uma obra da educação profissional superior ao aluno do secundário. Ao mestre cabe "saber distinguir qual convém melhor ao seu aluno, não só quanto á força intelectual que este já possúe, como no sentido de aumentá-la sempre um pouco mais, dando-lhe um vigor novo que ainda não possui” ( PIRES, 1892c: 114). Completa dizendo que não adianta o mestre exigir do seu aluno um esforço de estudo que vá além do intelecto do educando, pois seria uma ação constrangedora, o que acabaria por prejudicar o desenvolvimento natural de diversos órgãos corporais levando, inclusive, ao adoecimento físico e mental.

Enfim, o diretor, nesta coluna sobre Higiene da Inteligência destaca que cabe ao mestre ter o cuidado de variar as disciplinas ensinadas e a distribuição do tempo para cada estudo e atividade. Ele destaca ser importante dosar atividades intelectuais com atividades físicas, o que contribuiria com uma nova postura educativa frente à construção da república brasileira.

Nessa perspectiva, a aprendizagem defendida pelo nosso intelectual é um processo múltiplo, em que são utilizadas estratégias diversas para aprender; as variantes dependem do período de desenvolvimento humano articulado aos aspectos biológico, psíquico e cultural de cada educando.

Quanto aos números 2 a 4 e 6, da revista em análise, volume 3, ano 1893, a seção Pedagogia - Prelecção aos Meus Anumnos: Ensino de Cousas, Octavio Pires tratou dos 
seguintes assuntos: animais vertebrados, aves, mamíferos e o corpo humano (aparelho digestivo e a alimentação).

A edição número 7 (1893a) tem uma coluna de Octavio Pires agradecendo o incentivo do Congresso Legislativo do Estado em subsidiar as publicações da referida revista a todos os professores primários do ensino público que não possuem, em outras palavras, condições financeiras, devido aos baixos salários, para adquirirem a Revista e até outros materiais de estudo que possam contribuir com o aperfeiçoamento da profissão docente. Entretanto, o diretor ressalta que nem todos os profissionais aproveitaram os ensinamentos publicados no espaço limitado do periódico. Segundo o diretor, "a razão principal d'estas divergências está em nossa própria educação do passado, que não nos habituou a amar com verdadeiro e vivo ardor as letras e as sciencias." (PIRES, 1893a: 97).

Mesmo diante de possíveis desprezos para com a leitura do periódico, este intelectual diz que terá o sentimento de dever cumprido, faz os votos de que, pelo menos para alguns poucos leitores, a revista possa produzir resultados satisfatórios, condizentes com o objetivo pelo qual a mesma fora criada.

O volume 3, número 9, da Revista Educação e Ensino, Octavio Pires (1893b) trata da credibilidade dos exames finais realizados nas escolas de ensino secundário. Segundo este mesmo autor, o período de exame era tido pelos estudantes como um momento de aflição, pois, caso não tivessem estudado o suficiente, seriam condenados à ignorância, fato que os colocava em situação de temor e vergonha perante os colegas e demais pessoas estranhas, além do desgosto que causariam aos pais ou benfeitores com o resultado final negativo. Se, ao contrário, o resultado fosse positivo, ainda assim era um momento de apreensão, pois talvez a nota não correspondesse ao esforço depreendido ao longo do ano letivo, sendo colocado abaixo da sua capacidade. Enfim, qualquer que fosse o caso, a época de exames finais era demarcada por sustos e apreensões, quando há sinceridade e, sobretudo, a imparcialidade das comissões examinadoras.

O diretor Octavio Pires (1893b) afirma que no início dos exames estes atos foram honrados com a lealdade e imparcialidade, mas que ao longo dos anos houve um afrouxamento do processo avaliativo, o que causou abalo na justiça e seriedade dos exames. A parcialidade toma o lugar da imparcialidade. Então, a avaliação que era um momento tenso de aflição, passa a ser "simples e puramente uma formalidade obrigada e não raro um verdadeiro pagode" (PIRES, 1893b: 129). Ainda, segundo o nosso intelectual, todo o cuidado de outrora dos examinadores levou "nas Academias da mais 
lisonjeira reputação literária: aureola fulgurante ao nome dos seus velhos preceptores.[...] Entretanto, pouco a pouco toda a credibilidade foi colocada se extinguindo, a ponto de se venderem “certificados de aprovações em preparatórios!!...”. (PIRES, 1893b: 130, grifo do autor).

Ele completa a "denúncia da credibilidade dos exames finais" dizendo que,

Como os atos preparatorianos, foram também os exames da primitiva Escola Normal descambando gradativamente para o torvelinho da imoralidade, de modos que um dia veio em que diplomas de normalistas foram conferidos a pessoas incompetentes e, dizem mesmo á baixa voz, a quem nem ao menos tinha o curso concluído!!... (PIRES, 1893b: 130, grifo do autor).

Aqui o diretor destaca, inclusive, a credibilidade da certificação de alguns professores primários. Isto posto, a nosso ver, acarreta mais uma vez na história educacional brasileira a fragilidade da formação profissional docente, o que acaba por influenciar a qualidade de todo um sistema educacional.

No ano de 1894, foram localizados os números 2 a 10 - volume 4, da Revista Educação e Ensino. No número 2, o diretor destina sua escrita ao Congresso Legislativo Paraense. Chama a atenção do Congresso para a importância da Instrução Pública Primária: "Nenhum outro problema desafia mais cuidado, esmero e reflexão da parte de um Congresso de legisladores" (PIRES, 1894a: 3). O diretor reforça, em seu texto, a importância dada pelos governos republicanos quanto a reformas e estudos para tornar a instrução elementar perfeita, próspera e disseminada entre a população. O diretor neste número agradece ainda ao Congresso pelo aumento nos vencimentos concedido aos mestres e reforça a necessidade de uma melhor remuneração a estes profissionais para que possam cumprir seus compromissos particulares, mantendo a reputação modesta e descente da vida íntima.

Sob a influência do discurso republicano, o volume 4, números de 3 a 5 , foi dedicado à análise do Projeto de Lei sobre a Instrução Pública Paraense. Dentre outros aspectos analisados pelo diretor, destacamos o art. $1^{\circ}$ do Projeto de Lei, que trata da gratuidade, da obrigatoriedade e da laicidade do ensino público do Estado do Pará.

O diretor Octavio Pires esclarece que não é contra a obrigatoriedade do ensino, mas destaca que ela deve ser verdadeira e não uma "pseudo-obrigação, apenas existente na lei”. Assim sendo, o autor faz defesa não só pela obrigatoriedade, mas também pela 
qualidade do ensino a ser ofertado. Ele faz essa defesa pontuando ao Congresso e aos leitores as condições geográficas do Estado, bem como a questão social e econômica da população e as condições reais da família quanto à educação dos filhos.

Ainda ao analisar o Projeto de Lei, o intelectual solicita a supressão do $14^{\circ}$ artigo, no qual é autorizado exame de provimento efetivo de professores elementares e adjuntos nas sedes das comarcas. Segundo Octavio Pires, no interior as relações parentais são muito mais presentes que em uma cidade grande, e isto pode ocasionar uma situação em que

pessoas incompetentes receberão, por mera condescendência, pela falsa ideia do não querer fazer mal, o seu placet de professor. [...] o único favorecido neste caso, assegurando-se-lhe um meio de vida à custa do erário público, outro tanto, porém, não acontecerá com a infância, que viera a ser a unicalesada, despiedosamente engazopada e roubada, vendo-se obrigada a receber um remendão de ofício por oficial. (PIRES, 1894b: 49).

Além disso, o intelectual analisa a formação dos professores, dizendo da dificuldade em encontrar "professores, e muito particularmente no Interior, que buscam ampliar os seus conhecimentos, investigando assumptos novos, adquirindo obras modernas, consultando autores, ouvindo e discutindo a opinião dos seus colegas" (PIRES, 1894b: 49).

O diretor ressalta a necessidade da formação contínua dos professores, entretanto, não faz nenhuma observação ao Congresso Estadual para que este investimento seja também do poder público, e não só de responsabilidade individual de cada profissional, mesmo compreendendo a formação num continuum, sobretudo para aqueles que trabalham com o ensino da sociedade.

No volume 4 da revista, número 7 , ano 1894, o diretor trata dos debates ocorridos em reunião do Congresso Paraense, no dia 30 de junho de 1894, em que duas questões sobre a Instrução Pública foram apresentadas: Lei-base, estabelecendo princípios para cada etapa do ensino mantido pelo Governo e o aumento dos vencimentos para os profissionais do magistério. Sobre a última, Octavio Pires (1894c), evidencia a dificuldade econômica pela qual os profissionais do magistério desde outrora vêm enfrentando. 
Nas edições 6 e 10 da revista, o professor normalista Octavio Pires dedica sua "conversa" com os leitores à autorização do Congresso para com o ensino do "desenho á mão livre". Diz como é importante este aprendizado pelas crianças.

Qualquer que seja o ramo de vida que atualmente se abrace, entre as Ciências ou Letras, ou mesmo entre as próprias Artes, tem a experiência demonstrado á sociedade que a habilitação no Desenho a mão-livre é uma necessidade imprescindível e de uma incontestável vantagem. E eis porque nos países adiantados do globo é esta aprendizagem obrigada, desde os primeiros dias em que a criança começa a receber as suas primeiras lições de leitura. (PIRES, 1894c: 81).

Octavio Pires destaca a importância do desenho para o desenvolvimento psíquico e motor da criança. Na primeira metade do século XX, Vigotsky constata em seus estudos e pesquisas a importância do desenho na construção da linguagem escrita infantil, “[...] o desenho e a escrita devem ser vistos como momentos diferentes de um processo essencialmente unificado [...]" (VIGOTSKY, 1988: 131), dessa maneira “[...] brincar e desenhar deveriam ser estágios preparatórios ao desenvolvimento da linguagem escrita" (1988: 134).

No volume 4, número 9, ano 1894, o texto do diretor se refere à análise das emendas realizadas pelos deputados no projeto $n^{\circ} 72$, relativo à Instrução Pública do Estado. Octavio Pires faz uma restrospectiva da base teórica educacional e conclui dizendo que percebe na aprovação do projeto novas perspectivas ao ensino popular paraense. Neste texto explicita a necessidade da atenção pública no que tange à formação do "mestre e direcção" e, por meio da regulamentação e organização da escola Normal, melhorará a educação em geral. Se manifesta a favor de uma pedagogia diferente daquela pautada na cultura exclusiva e brutal da memória. "Reformar os methodos e os mestres: eis em que consiste o progresso todo do ensino e o meio mais eficaz de vencer a mais endurecida de todas as rotinas - a rotina pedagogica”. E, ainda, faz votos para que a indiferença não assuma o comportamento daqueles responsáveis em aperfeiçoar e impulsionar a instrução, assim, será possível que a educação se torne um fato real (PIRES, 1894d:132).

Interessante observar que no número 9 da revista ficam evidentes duas questões: a formação dos professores e o currículo escolar, questões que até hoje se fazem presentes nas discussões educacionais e estão longe de serem esgotadas, diante do descaso para com a educação popular brasileira. 
Do ano de 1895, foi possível localizar no Centro Cultural Tancredo Neves CENTUR os exemplares da Revista Educação e Ensino números 7 e 9, sendo que no número 7 o diretor Octavio Pires comunica aos leitores que, a partir da referida edição, a revista contará com a colaboração de diversos redatores, dentre eles, das professoras Maria Guajarina de Lemos, Sirena Valente, Maria Valmont e Maria José Baena. Destacamos estes nomes por sabermos que, historicamente, não era comum mulheres terem a chance de participar de espaços comandados exclusivamente por homens, mesmo que o objetivo da revista estivesse direcionado, principalmente, às professoras primárias.

No volume 5, número 9, é tratado o ensino do canto nas escolas, bem como o comunicado do Congresso Pedagógico. Sobre o canto, Octavio Pires diz que este "na escola não é somente um descanso, é também um exercicio que educa o espirito, toca o coração e deleita o ouvido, quando, bem entendido, é executado, cuidadosamente." (PIRES, 1895: 81).

Octavio Pires também participou como $1^{\circ}$ secretário do Congresso Pedagógico, movimento destinado a professores, diretores e estabelecimentos oficiais de ensino público e particular. Segundo ele, o professorado do Estado demonstrou ter sempre atenção para com tudo àquilo que significasse um progresso e um alento às variadas funções da pedagogia.

O professor-normalista e intelectual Octavio Pires integrou a Associação Propagadora do Ensino, conforme nota informativa publicada no Jornal Folha do Norte, em 06 de janeiro de 1896. A participação na associação corrobora o papel de intelectual orgânico desenvolvido por Octavio Pires junto à educação paraense no final do século XIX e início do século XX.

Diante dos escritos do professor-normalista Octavio Pires se percebe a presença ativa nas discussões políticas e educacionais de ordem positivista e liberal presentes na constituição do estado republicano brasileiro.

\section{Palavras Finais...}

Consideramos que a contribuição de Octavio Pires é de fundamental importância para a materialização da publicação da Revista Educação e Ensino, no final do século XIX, período de grande efervescência no que tange ao início da República. 
A Revista foi um veículo de comunicação/formação, que possibilitou aos professores, sobretudo, professoras primárias, a reflexão, discussão e proposição sobre os inúmeros desafios pertencentes à carreira docente e à Instrução Pública do Estado a partir de referenciais nacionais e internacionais, pois havia artigos publicados na Revista que tratavam de questões presentes em países do continente europeu e dos Estados Unidos da América.

A publicação da Revista possibilitou ainda ao professorado paraense ampliação de conhecimentos docentes no que se refere ao aspecto curricular, quando trata de assuntos diretamente ligados ao programa escolar, ao desenvolvimento humano e a legislação estadual paraense.

Assim, percebemos nos artigos de Octavio Pires preocupação para com a melhoria da ação pedagógica dos professores. Recorremos aos estudiosos do século $\mathrm{XX}$, dentre eles, Lima (2008: 19), quando diz que o educador deve adequar sua prática pedagógica às possibilidades de desenvolvimento e aprendizagem de seus educandos. As aprendizagens escolares são a efetivação das potencialidades da espécie. Resultam da articulação entre as possibilidades do desenvolvimento e as atividades que as efetivam, atividades que são ensinadas pelo educador.

Como é função do educador ensinar os conhecimentos sistematizados, é necessário que este profissional esteja bem preparado. Para tanto, nosso intelectual em várias edições da Revista Educação e Ensino reivindicou maior investimento na formação de professores por parte do poder público e, ao mesmo tempo, chamou a atenção do professorado para que se dedicassem mais aos estudos necessários ao exercício da profissão docente.

Ao desvelar a preocupação de Octavio Pires para com a formação de professores paraense, buscamos em Marcelo Garcia (1999), o conceito de formação contínua sendo “atividade que o professor em exercício realiza com uma finalidade formativa - tanto de desenvolvimento profissional como pessoal, individualmente ou em grupo - para um desempenho mas eficaz das suas tarefas atuais ou que o preparem para o desempenho de novas tarefas" (MARCELO GARCIA, 1999: 136).

Entendemos, desse modo, que o pensamento do intelectual orgânico Octavio Pires sobre a educação brasileira e, em particular, a educação paraense, ainda está presente em nossos dias.

Ao compreendermos Octavio Pires como intelectual orgânico o fazemos num contexto em este homem assumiu ativamente essa função na sociedade (GRAMSCI, 
2001) paraense ao se dedicar às questões educacionais do Estado em várias frentes de luta, seja como professor-normalista, diretor da Revista Educação e Ensino, sócioproprietário do Colégio Minerva, seja como integrante do Congresso Pedagógico e da Associação Propagadora do Ensino.

Salientamos a proposição, aos estudiosos e pesquisadores da educação brasileira, principalmente paraense, que, em outras oportunidades, seja retomada a análise aprofundada da legislação aprovada pelo Congresso Estadual no final do século XIX, assim teremos um panorama dos avanços e retrocessos ocorridos na legislação educacional, indicando possíveis intervenções na busca de melhorias em nossa educação.

\section{Fontes}

PIRES, Octavio (1891a). Pedagogia. Revista Educação e Ensino, v. 1, n. 8. (1891b). Pedagogia. Revista Educação e Ensino, v. 1, n. 9. (1891c). Pedagogia. Revista Educação e Ensino, v. 1, n. 10. (1892a). Pedagogia. Revista Educação e Ensino, v. 2, n. 1. (1892b). Pedagogia. Revista Educação e Ensino, v. 2, n. 2. (1892c). Pedagogia. Revista Educação e Ensino, v. 2, n. 8. (1893a). Pedagogia. Revista Educação e Ensino, v. 3, n. 7. (1893b). Pedagogia. Revista Educação e Ensino, v. 3, n. 9. (1894a). Pedagogia. Revista Educação e Ensino, v. 4, n. 2. (1894b). Pedagogia. Revista Educação e Ensino, v. 4, n. 4. (1894c). Pedagogia. Revista Educação e Ensino, v. 4, n. 6. (1894d). Pedagogia. Revista Educação e Ensino, v. 4, n. 9. (1895). Pedagogia. Revista Educação e Ensino, v. 5, n. 9.

\section{Referências bibliográficas}

BLOCH, Marc (1976). Introdução à História. 3. ed. Lisboa: Publicações EuropaAmérica.

BOMENY, Helena (2003). Quando os números confirmam impressões: desafios na educação brasileira. Rio de Janeiro: CPDOC. Disponível em: <http://cpdoc.fgv.br/producao_intelectual/arq/1354.pdf>. Acesso em: 17 de jul. 2015.

FILIPE ALBERTO PATRONI MARTINS MACIEL. Disponível em: PARENTE. <http://www.consciencia.org/filipe-alberto-patroni-martins-maciel-parente>. Acesso em: 13 de jul. 2015.

GIL, Antonio Carlos (2002). Como elaborar projetos de pesquisa. 4. ed. São Paulo: Atlas.

GRAMSCI, A (2001). Cadernos do cárcere. Os intelectuais. O princípio educativo. Jornalismo. Volume 2, Rio de Janeiro: Civilização Brasileira.

LAURO SODRÉ. Disponível em: <https://pt.wikipedia.org/wiki/Lauro_Sodr\%C3\%A9>. Acesso em: 13 de jul. 2015. 
LIMA, Elvira. Currículo e Desenvolvimento Humano (2008). In: BRASIL/MEC/SEB. Indagações sobre currículo. Brasília: MEC/SEB.

MARCELO GARCIA, C (1999). Formação de Professores: para uma mudança educativa. Porto, Portugal: Porto Editora.

PÁDUA, Elisabete. M. M. de (1997). O processo de pesquisa. In: PÁDUA, Elisabete M. M. de. Metodologia da pesquisa: abordagem teórico-prática. Campinas: Papirus, p.62.

PARÁ. Jornal Folha do Norte. n. 6, p. 2, 06 de janeiro de 1896.

RÉMOND, René (2003). Por uma história politica. Trad. Dora Rocha. 2. ed. Rio de Janeiro: Editora FGV.

SAVIANI, Dermeval (2009). Formação de professores: aspectos históricos e teóricos do problema no contexto brasileiro. Revista Brasileira de Educação. v. 14 n. 40 jan./abr. Disponível em: <http://www.scielo.br/pdf/rbedu/v14n40/v14n40a12.pdf>. Acesso em: 13 abr. 2015.

SEMERARO, G. (2006). Intelectuais "orgânicos" em tempos de pós-modernidade. Caderno Cedes, Campinas, v. 26, n. 70, pp. 373-391, set./dez. Disponível em: <http://www.cedes.unicamp.br>. Acesso em: 28 mai.2015.

SIRINELLI, Jean-François (2003). Os intelectuais. In: RÉMOND, René. Por uma história política. Trad. Dora Rocha. 2. ed. Rio de Janeiro: Editora FGV.

SANTOS, Jordana S (2009). Gramsci e o papel dos intelectuais nos movimentos sociais. Revista Espaço Acadêmico, UEM, Maringá, n. 102, Novembro. Disponível em:

<http://eduem.uem.br/ojs/index.php/EspacoAcademico/article/viewFile/7128/4819>. Acesso em: 05 jun. 2015.

SILVA, Antonia R. Favacho da. et.al. O Liceu Paraense no início do século XX: breves apontamentos. Disponível em: <http://www.histedbr.fe.unicamp.br/acer_histedbr/seminario/seminario7/TRABA LHOS/A/Antonia\%20Roseane\%20Favacho\%20Da\%20Silva.pdf>. Acesso em: 13 nov. 2016.

VIANA, Arthur (1987). Esboço retrospectivo da Instrução Pública no Pará. In: PARÁ/SEDUC. A educação no Pará - documentário. Belém: SEDUC.

VIGOSTSKY, Lev (1988). A formação social da mente: o desenvolvimento dos processos superiores. São Paulo, Martins Fontes.

Artigo recebido em 03 de março de 2016.

Aprovado em 02 de novembro de 2016. 